\title{
Tomato Leaf Curl Sudan Virus (TLCSDV) causing leaf curl disease on a new host Amaranthus cruentus L.
}

\author{
Sayed Sartaj Sohrab
}

\author{
Special Infectious Agents Unit; King Fahd Medical Research Center, King Abdulaziz University, Jeddah, Saudi \\ Arabia
}

\section{*Corresponding author: ssohrab@kau.edu.sa}

\begin{abstract}
Amaranthus leaf curl disease symptom was observed in the farmer's field based at Jeddah, Saudi Arabia. This crop used as leafy vegetables in many countries. In this study, a field survey was conducted in April 2014 and naturally infected Amaranthus leaf samples were collected to identify the associated virus with leaf curl disease. The causative agent was transmitted through whiteflies (Bemisia tabaci) from naturally infected leaves to healthy Amaranthus seedlings. The begomovirus infection was identified by PCR by using specific primers. The full viral genome was amplified by rolling circle amplification. The presence of betasatellites was also confirmed by using betasatellites specific primers. The full viral genomes as well as betasatellites were amplified, cloned and sequenced. The full-length viral genome sequence analysis showed the highest (99.9\%) homology with Tomato leaf curl Sudan Virus infecting tomato reported from the Arabian Peninsula. The betasatellites sequence analysis showed the highest identity (99.3\%) with Tomato leaf curl betasatellites-Yemen. The phylogenetic analysis was performed by using both full as well as betasatellites genome and full genome formed the closest cluster with Tomato leaf curl Sudan virus while betasatellites genome formed closed cluster with tomato yellow leaf curl Yemen betasatellites. The recombination analysis was performed and results showed that the associated virus could be a variant of Tomato leaf curl Sudan virus, a virus that occurs in Sudan, Yemen and Arabian Peninsula. This is the first report that about the Tomato leaf curl Sudan virus causing leaf curl disease on a new host Amaranthus in Jeddah, Saudi Arabia.
\end{abstract}

Key words: Amaranthus, Leaf curl disease, Begomovirus, Phylogenetic and Recombination relationships, Saudi Arabia. Abbreviations: AgEV_Ageratum enation virus, CaCV_Capsicum chlorosis virus, CMV_Cucumber mosaic virus, ChiLCV_Chili leaf curl virus, PALCV_Papaya leaf curl virus, ToLCSDV_Tomato leaf curl Sudan virus, TYLCV_Tomato yellow leaf curl virus.

\section{Introduction}

Amaranthus belongs to the family, Amaranthaceae with approximately 60 species and mostly are known as cosmopolitan weeds (A. retroflexus L., A. hybridus L., A. powellii L. and A. spinosus L.). Amaranthus is broad leaf and warm-seasoned plant grown in Asia, South-East Asia, Manchuria and North America for various purposes like ornamental, edible greens, leafy vegetable, forage crops, herbs and grain (Hauptli and Jain 1977, Bhatia 2005). Additionally, Amaranthus is a very rich source of iron, calcium, zinc, magnesium, Vitamins (A, B, C) and cholesterol-lowering soluble fiber (http://archive.indianexpress.com/news/thirdmillenniumgrain-highprotein-amaranth-is-rich-in-ironcalcium/ 1111172/). The Amaranthus cultivation is being affected by many viral diseases (Horvath 1991; Costea and Tardif, 2003) and among them, the most common viruses are known as Amaranthus leaf mottle virus (Segundo et al., 2007), Amaranthus mosaic 'potyvirus' (Brunt, 1996), Cucumber mosaic virus (CMV) (Srivastava and Raj, 2004) and begomoviruses like; Tomato yellow leaf curl virus (TYLCV) ( Abou-Jawdah et al., 1999), Chili leaf curl virus (ChiLCV) (George et al., 2014), Ageratum enation virus (AgEV) (Raj et al., 2008; Srivastava et al., 2013), Papaya leaf curl virus (PALCV) (Srivastava et al., 2015) and Capsicum chlorosis virus (CaCV) (Sharma and Kulshrestha 2014). Begomoviruses belongs to family Geminiviridae are serious problems for many crops globally. The family Geminiviridae has now been reported to have seven genera known as Mastrevirus, Curtovirus, Begomovirus, Topocuvirus, Eragrovirus, Turncurtovirus, Becurtovirus (Muhire et al., 2014; Brown et al., 2015; Varsani et al., 2014). Members of the genus begomovirus have circular single-stranded DNA (ssDNA) with either a mono-or bipartite genome.The bipartite begomovirus genome has two ssDNA molecules $(\sim 2.7 \mathrm{~kb})$, known as DNA-A and DNA-B while mono-partite begomovirus has only DNA-A with satellite molecule known as betasatellites (Briddon et al., 2003). Betasatellites are small $(\sim 1.4 \mathrm{~kb})$, highly diverse with circular ssDNA. The betasatellites replication, movement, and transmission between plants are mediated by their helper virus. Betasatellites have an ORF; beta $\mathrm{C} 1$, an adenine-rich region, and a satellite conserved region with $45-93 \%$ sequence identity (Sivalingam et al., 2010). The dicotyledonous plants are infected by begomovirus transmitted by whitefly vector (Bemisia tabaci) in a persistent manner. Globally, the whiteflies have become serious pathogens for many dicotyledonous crops in tropical, sub-tropical and warmer temperate regions and mostly Solanaceous crops are being affected by begomovirus in East and Southeast Asia (Kenyon et al., 2014; Idris and Brown 2005). The whitefly posing a serious threat to global food security and there is an urgent need to develop effective strategies to control crop loss and 
manage the begomoviral disease. Currently, the natural occurrence of mono-partite begomoviruses and their associated alpha and betasatellites are reported to be endemic in Eastern Hemisphere ( Briddon et al., 2001; Idris et al., 2014).

In this study, the associations of begomovirus with leaf curl disease of Amaranthus from; Jeddah, Saudi Arabia has been discussed. In April 2014, during field survey, leaf curl disease was observed on Amaranthus plant growing in and around the tomato growing farmer's field at Jeddah, Saudi Arabia. Severe leaf curl infection was also observed in tomato crops. Naturally infected Amaranthus leaf samples exhibiting typical leaf curl symptoms were collected from natural open plots of Jeddah, Saudi Arabia. The causative agent was detected by begomovirus specific PCR, efficiently transmitted by whitefly vector and characterized at molecular level by cloning and sequencing of full genome and betasatellites and analyzing the sequence identity, phylogenetic relationship with selected begomovirus isolates from different locations. The sequence identity and phylogenetic analysis results strongly support the causative agent is a variant of Tomato leaf curl Sudan virus (ToLCSDV), a virus that has been reported earlier to cause tomato leaf curl disease in Sudan, Oman and Yemen. The association of begomovirus with leaf curl disease on various crops in Arabian Peninsula has been published in many reports (Ajlan et al., 2007; Khan et al., 2008; Idris et al., 2012; Akhtar et al., 2014; Idris et al., 2011; Khan et al., 2013a; (Ajlan et al., 2007; Khan et al., 2008; Idris et al., 2012; Akhtar et al., 2014; Idris et al., 2011; Khan et al., 2013b Al-Saleh et al., 2014; Hosseinzadeh et al., 2014; Idris et al., 2014).

\section{Results}

Field survey, collection of sample and transmission of virus by whiteflies

Amaranthus plants were growing in and around infected tomato fields and approximately $90 \%$ plants were observed to be infected with leaf curl disease as compared to healthy ones (Figure. 1 a \& 1 b). The whiteflies (B. tabaci) were also observed in the infected Amaranthus and tomato leaves. The causative agent was successfully transmitted to healthy Amaranthus seedling. Total 11 samples were collected from symptomatic and non-symptomatic plants and processed for virus detection. The causative agent was successfully transmitted to $14 / 21$ healthy tomato seedling by whiteflies inoculation which further developed similar leaf curl symptoms after 18-20 days post inoculation (dpi) as observed in the field.

\section{Molecular detection of virus, cloning and sequencing of viral genome}

The begomoviral infection was confirmed by PCR and $~ 856$ bp amplicon was observed in 9 samples by using begomovirus-specific primers. Two clones were obtained from betasatellites genome but only one sequence was used for further analysis. Restriction of RCA products with EcoRI yielded fragments of $\sim 2.8 \mathrm{~kb}$ from infected samples and cloned into pGEM7Zf + (Promega, Madison, WI) from the RCA-amplified products. The confirmed clones were sequenced bi-directionally at our special infectious agents unit (SIAU), King Fahd Medical Research Center, King Abdulaziz University, Jeddah, Saudi Arabia. Assembled sequences from both full length and betasatellites genomes were submitted to GenBank under the accession numbers (KT033710 \& KT 199104).

\section{Sequence, phylogenetic and recombination analysis}

The complete genome contained 2789 nucleotides (nt) encoding six potential open reading frames (ORFs): V1 (coat protein), V2 (pre-coat protein) in virion sense strand while $\mathrm{C} 1$ (replication associated protein), C2 (transcription activator protein), C3 (replication enhancer protein) and C4 (C4 protein) in complementary sense, which were typical of begomovirus genome. The betasatellites genome was found to have 1359 nucleotides (nt). Based on full genome sequences; BLAST analysis of the identified begomovirus isolate in this study (KT033710) showed highest 99.9\% sequence identity with ToLCSDV-(HG530539) reported from Saudi Arabia and lowest identity was $69.0 \%$ with PALCV-(JN135233) infecting Amaranthus reported from India followed by $91.5 \%-92-4 \%$ with other ToLCSDV reported from Oman. The nucleotide sequence identity was varied from $91-92 \%$ with TYLCV reported from Saudi Arabia. Interestingly, three other begomoviruses reported infecting Amaranthus in India, showed only 69\% identity (PALCV-JN135233), 71.7\% (AgEV-EU867513) and 71.8\% (ChiLCV-KF471061) with our isolate. The highest amino acid sequence identity was observed with ToLCSDVHG530539 in all the 6 proteins $(99.6 \%$-V2, 99.8\%-V1, 99.7\%-C3, 99.8\%-C2, 99.9-C1, and 99.8-C4) respectively, with respective sequences of selected begomovirus isolates (Table 1).

Since the association of a betasatellite molecule with ToLCSDV has been reported earlier (Idris et al., 2014), a separate PCR was performed using betasatellite specific primers (Briddon et al., 2002). An amplicon of $\sim 1.4 \mathrm{~kb}$ was obtained from infected samples by PCR, indicating the presence of betasatellite. The highest nucleotide identity (99.3\%) was found with Tomato leaf curl Yemen betasatellites (ToLCYEB) (JF919719) and the lowest (45.7\%) was observed with Ageratum leaf curl betasatellitesIndia (JQ710745) (Table 2).

To analyze the phylogenetic relationships of identified begomovirus isolate used under this study (KT033710) with other selected begomovirus isolates, a neighbor-joining phylogenetic tree was generated using Molecular Evolutionary Genetics Analysis tool (MEGA v 6.1) (Tamura et al., 2013). The phylogenetic analysis results based on complete genome sequences of selected begomovirus isolates indicates that the identified virus is a variant of either ToLCSDV, TYLCV as the closest cluster was observed with two begomovirus groups ToLCSDV, TYLCV and other three Indian begomovirus isolates reported from Amaranthus. The isolate formed closed cluster with ToLCSDV from other crops and showed the closest relationships with ToLCSDVTomato (HG530539, JN591386), Tobacco-(JF919733) reported from Saudi Arabia, Yemen and Oman (Figure. 2). Based on nucleotide sequence identity and close phylogenetic relationships with ToLCSDV and as per new criteria proposed for begomovirus classification in the ICTV report (Fauquet et al., 2008), the begomovirus isolate associated with leaf curl disease of Amaranthus from Saudi Arabia was identified as a variant of ToLCSDV. In a phylogenetic study based on betasatellites, the closest relationship was observed with ToLCYEB isolates infecting tobacco and tomato reported from Yemen (Figure. 3). 
Table 1. Pairwise (\%) sequence identities of DNA genome of begomovirus under study (KT 033710) with selected begomoviruses at nucleotide (nt) and amino acid (aa) levels.

\begin{tabular}{|c|c|c|c|c|c|c|c|c|c|c|}
\hline Accession No & Abbreviation & Host & Location & \multicolumn{7}{|c|}{ Percent sequence identity matrix at nucleotides and amino acid level } \\
\hline & & & & $\begin{array}{l}\text { DNA-A } \\
\text { Full (nt) } \\
\end{array}$ & V2 (aa) & $\begin{array}{l}\text { V1 } \\
\text { (aa) }\end{array}$ & $\begin{array}{l}\mathrm{C} 3 \\
\text { (aa) }\end{array}$ & $\begin{array}{l}\mathrm{C} 2 \\
\text { (aa) }\end{array}$ & $\begin{array}{l}\mathrm{C} 1 \\
\text { (aa) }\end{array}$ & $\begin{array}{l}\text { C4 } \\
\text { (aa) }\end{array}$ \\
\hline HG530539 & ToLCSDV & Tomato & S.Arabia & 99.9 & 99.6 & 99.8 & 99.7 & 99.8 & 99.9 & 99.8 \\
\hline JF919733 & ToLCSDV & Tobacco & Yemen & 91.5 & 95.6 & 97.2 & 85.8 & 85.9 & 91.6 & 74.0 \\
\hline JF919734 & ToLCSDV & Tobacco & Yemen & 90.3 & 93.9 & 97.2 & 87.3 & 87.4 & 88.8 & 56.0 \\
\hline KC845301 & TYLCV & Tomato & S.Arabia & 91.6 & 62.3 & 98.1 & 85.8 & 88.1 & 91.6 & 69.0 \\
\hline KF561125 & TYLCV & Tomato & S.Arbia & 91.5 & 94.8 & 91.0 & 73.1 & 86.6 & 84.8 & 68.6 \\
\hline KF040453 & TYLCV & Tomato & S.Arabia & 91.2 & 98.2 & 91.0 & 74.6 & 89.6 & 82.8 & 67.6 \\
\hline JN591386 & ToLCSDV & Tomato & Oman & 92.2 & 96.5 & 98.0 & 88.0 & 88.1 & 86.2 & 77.0 \\
\hline FJ956700 & ToLCV & Tomato & Oman & 88.5 & 93.1 & 77.9 & 85.0 & 81.4 & 75.7 & 73.0 \\
\hline KF444467 & ToLCSDV & green bean & S.Arabia & 89.7 & 92.3 & 96.4 & 85.8 & 85.9 & 87.1 & 71.0 \\
\hline KF561125 & TYLCV & Tomato & S.Arabia & 91.5 & 98.2 & 91.0 & 73.1 & 86.6 & 84.8 & 68.6 \\
\hline HE819244 & ToLCSDV & Tomato & Oman & 91.5 & 98.2 & 91.8 & 74.6 & 88.8 & 85.7 & 70.0 \\
\hline JN591385 & ToLCSDV & Tomato & Oman & 91.2 & 98.2 & 92.2 & 75.3 & 87.4 & 85.9 & 77.0 \\
\hline JN591386 & ToLCSDV & Tomato & Oman & 92.1 & 98.2 & 98.0 & 88.0 & 88.1 & 86.2 & 77.0 \\
\hline AY044139 & ToLCSDV & Tomato & Sudan & 92.4 & 98.2 & 97.2 & 85.8 & 88.1 & 93.8 & 82.0 \\
\hline JX483708 & ToLCSDV & Tomato & Sudan & 91.9 & 95.6 & 97.2 & 85.8 & 81.4 & 93.3 & 75.0 \\
\hline JF919731 & ToLCSDV & Tomato & Yemen & 89.7 & 96.5 & 96.8 & 78.3 & 77.0 & 91.6 & 69.0 \\
\hline EF110891 & ToLCSDV & Tomato & Yemen & 89.7 & 96.5 & 96.8 & 78.3 & 77.0 & 91.6 & 69.0 \\
\hline КC763630 & ToLCSDV & Tomato & Sudan & 88.3 & 90.5 & 96.1 & 86.5 & 87.4 & 91.0 & 72.0 \\
\hline AY044137 & ToLCSDV & Tomato & Sudan & 88.5 & 93.9 & 97.2 & 85.8 & 81.4 & 89.9 & 72.0 \\
\hline AY044138 & ToLCSDV & Tomato & Sudan & 82.9 & 93.9 & 76.3 & 82.8 & 84.4 & 93.0 & 66.0 \\
\hline GU180085 & ToLCSDV & Tomato & Sudan & 88.5 & 92.2 & 96.8 & 85.8 & 82.2 & 90.2 & 72.0 \\
\hline DQ358913 & TYLCMV & Tomato & Ethiopia & 83.2 & 94.8 & 76.7 & 85.0 & 86.6 & 90.2 & 72.0 \\
\hline DQ644565 & TYLCV & Tomato & Oman & 78.9 & 93.9 & 77.9 & 83.5 & 82.9 & 82.4 & 71.0 \\
\hline KF471061 & ChiLCV & Amaranthus & India & 71.8 & 68.9 & 72.7 & 70.8 & 66.6 & 79.2 & 44.1 \\
\hline JN135233 & PALCV & Amaranthus & India & 69.0 & 72.2 & 73.9 & 65.6 & 62.2 & 68.6 & 37.0 \\
\hline EU867513 & AgEV & Amaranthus & India & 71.7 & 72.4 & 73.9 & 62.6 & 61.4 & 78.9 & 56.0 \\
\hline GU076448 & TYLCV & Tomato & Iran & 83.7 & 92.2 & 77.9 & 83.5 & 82.2 & 81.2 & 66.0 \\
\hline KC106648 & TYLCV & Tomato & Iran & 79.1 & 92.2 & 78.2 & 82.0 & 80.0 & 80.0 & 38.0 \\
\hline
\end{tabular}

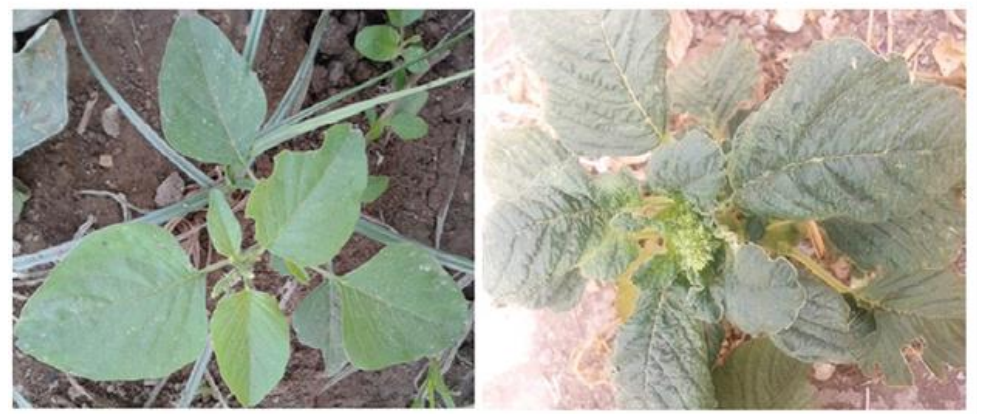

Figure. 1a. Healthy Amaranthus cruentus plant, Figure. 1b. Infected Amaranthus cruentus plant showing severe leaf curl stunting symptoms as compared with healthy plant.

Recombination analysis was carried out with full genome sequences of selected begomovirus isolates using the RDP4 program (Martin et al., 2015) Three of these algorithms, RDP $\left(P 1.657 \times 10^{-14}\right)$, GENCONV $\left(P 1.274 \times 10^{-15}\right)$, MaxChi $(P$ $\left.7.395 x^{10-14}\right)$, Chimera $\left(P 8.767 x^{10-13}\right)$, Si Scan $\left(P 3.509 x^{10-35}\right)$ and $3 \mathrm{Seq}\left(P 1.328 \times \times^{10-12}\right)$ predicted that the genome of the herein newly described ToLCSDV variant exhibit evidence of inert-specific recombination. The boot scan and RDP analysis of the ToLCSDV-Amaranthus genome together indicated definite evidence of recombination within the viral genome. Two recombinant fragments (co-ordinates 2025 to 2742 in the $\mathrm{C} 1$ gene and 1945 to 2678 toward the $3^{\prime}$ end of the Rep gene) were detected and these fragments shared high levels of sequence identity with ToLCSDV-HG-530539-
S.Arabia (99.9\% identity). ToLCSDV-Saudi Arabia was indicated as the major parent and ToLCSDV-Mir-Oman (JM591386) minor parent and ToLCSDV-Yemen-JF919733 was found as a recombinant isolate.The recombination analysis results suggest that the ToLCSDV-Amaranthus isolate evolved either from ToLCSDV-Oman or Yemen by recombination (Table 3).

\section{Discussion}

Amaranthus is an important subsidiary food crops in the tropical and subtropical highlands of Asia and South America and utilized as food grains, leafy vegetables, and forage crops in America, China, Greece, Italy, Russia, Nepal, and India. 
Table 2. Pairwise (\%) sequence identities of betasatellites under study (ToLCSDB-Amaranthus-KT199104) with selected betasatellites at nucleotide (nt) levels.

\begin{tabular}{|c|c|c|c|c|}
\hline Accession Nos. & Acronyms & Location & Host & $\%$ identity \\
\hline JF919717 & ToLCYEB & Yemen & Tobacco & 99.1 \\
\hline JF919718 & ToLCYEB & Yemen & Tobacco & 99.2 \\
\hline JF919719 & ToLCYEB & Yemen & Tobacco & 99.3 \\
\hline JF919720 & ToLCYEB & Yemen & Tobacco & 99.1 \\
\hline JF919721 & ToLCYEB & Yemen & Tobacco & 99.1 \\
\hline JF919722 & ToLCYEB & Yemen & Tobacco & 99.0 \\
\hline NC_010126 & TYLC $\beta-O m$ & Oman & Tomato & 49.5 \\
\hline DQ644566 & TYLC $\beta 01-O m$ & Oman & Tomato & 49.5 \\
\hline HG969297 & TYLC $\beta-O m$ & Oman & Papaya & 49.0 \\
\hline HG969296 & TYLC $\beta-O m$ & Oman & Papaya & 48.0 \\
\hline HE800552 & TYLC $\beta-O m$ & Oman & Tomato & 49.1 \\
\hline HE800551 & TYLC $\beta-O m$ & Oman & Tomato & 49.1 \\
\hline HE800550 & TYLC $\beta-O m$ & Oman & Tomato & 48.4 \\
\hline HE800549 & TYLC $\beta-O m$ & Oman & Tomato & 49.1 \\
\hline HE800548 & TYLC $\beta-O m$ & Oman & Tomato & 49.1 \\
\hline HE800547 & TYLC $\beta-O m$ & Oman & Tomato & 49.1 \\
\hline HE800546 & TYLC $\beta-O m$ & Oman & Tomato & 49.5 \\
\hline HE800545 & TYLC $\beta-O m$ & Oman & Tomato & 48.6 \\
\hline HE800544 & TYLC $\beta-O m$ & Oman & Tomato & 48.7 \\
\hline HE800543 & TYLC $\beta-O m$ & Oman & Papaya & 47.8 \\
\hline HE800542 & TYLC $\beta-O m$ & Oman & Capsicum & 49.3 \\
\hline HE800541 & TYLC $\beta-O m$ & Oman & Capsicum & 49.4 \\
\hline HE800540 & TYLC $\beta-O m$ & Oman & Capsicum & 49.3 \\
\hline KJ396939 & OkLCV satDNA-10 & Jordan & Tomato & 46.0 \\
\hline KF471033 & TYLCTHB & India & Amaranthus & 47.8 \\
\hline JQ710745 & AgeLCB & India & Amaranthus & 45.7 \\
\hline NC_004903 & TYLCTHV $\beta$ & Thailand & Tomato & 47.2 \\
\hline DQ641714 & TYLCVV $\beta$ & Vietnam & Tomato & 48.5 \\
\hline NC_007485 & TYLCMV $\beta$ & Mali & Tomato & 47.6 \\
\hline КС677734 & ToLCJaB & Java & Tomato & 47.5 \\
\hline
\end{tabular}

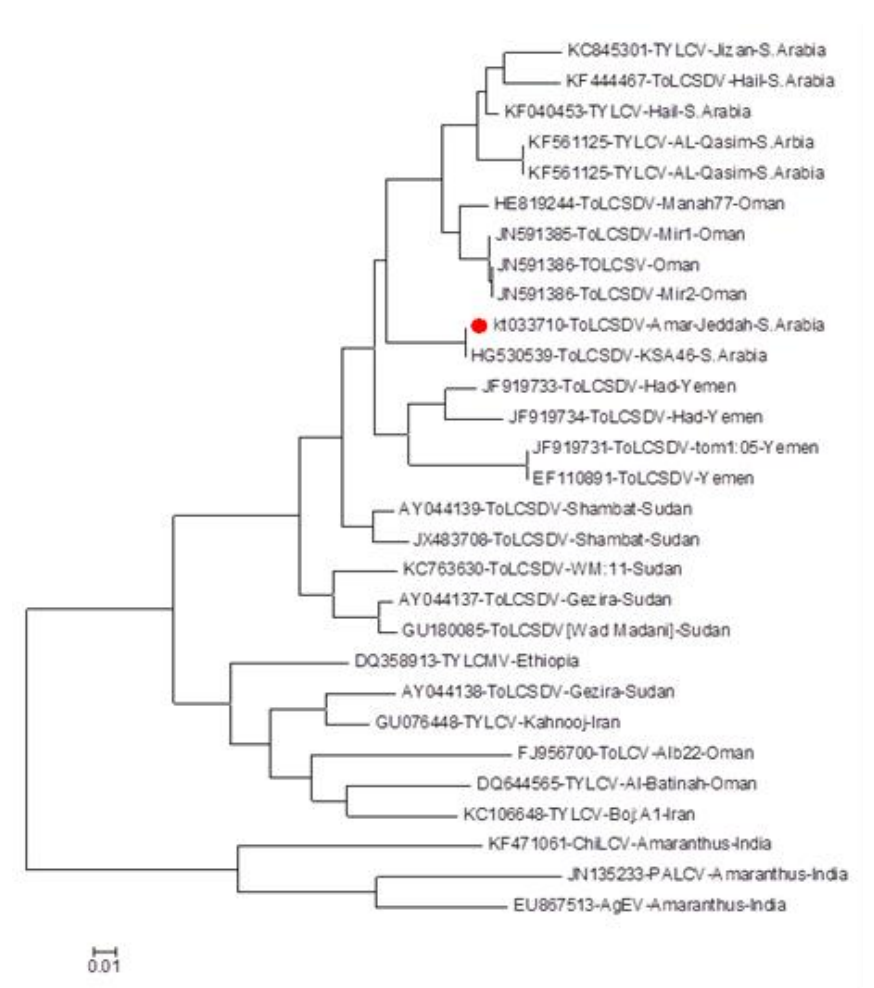

Figure 2. Phylogenetic relation ships of begomovirus genome under study with selected strains (selected based on full DNA -A BLASTn analysis) determined by NJ method within MEGA v6.1 with 1000 bootstrap replicates. 
Table 3. Recombination analysis of Tomato leaf curl Sudan virus isolate-Amaranthus using the RDP 4.0.

\begin{tabular}{|c|c|c|c|c|c|c|c|c|c|}
\hline Break & point & & & & & Detection $\mathrm{N}$ & hods & & \\
\hline Start & End & Minor Parent & Major Parent & RDP & GENCONV & MaxChi & Chimaera & SiScan & $3 \mathrm{Seq}$ \\
\hline 2025 & 2742 & $\begin{array}{l}\text { ToLCSDV- } \\
\text { SA(530539) }\end{array}$ & $\begin{array}{l}\text { ToLCSDV- } \\
\text { Mir-Oman } \\
\text { (JM591386) }\end{array}$ & $1.352 \times 10^{-11}$ & $1.176 \times 10^{-11}$ & $7.263 x^{10-11}$ & $7.762 \times 10^{-11}$ & $2.421 x^{10-}$ & $\begin{array}{c}1.134 x^{10-} \\
11\end{array}$ \\
\hline 1945 & 2678 & $\begin{array}{l}\text { ToLCSDV- } \\
\text { SA(530539) }\end{array}$ & $\begin{array}{l}\text { ToLCSDV- } \\
\text { Yemen- } \\
\text { JF919733 }\end{array}$ & $1.231 \times 10^{-10}$ & $1.154 \times 10^{-15}$ & $6.237 x^{10-11}$ & $7.348 \times 10^{-11}$ & $2.191 x^{10-}$ & $1.326 \times^{10-}$ \\
\hline
\end{tabular}

curl Thailand betasatellites,

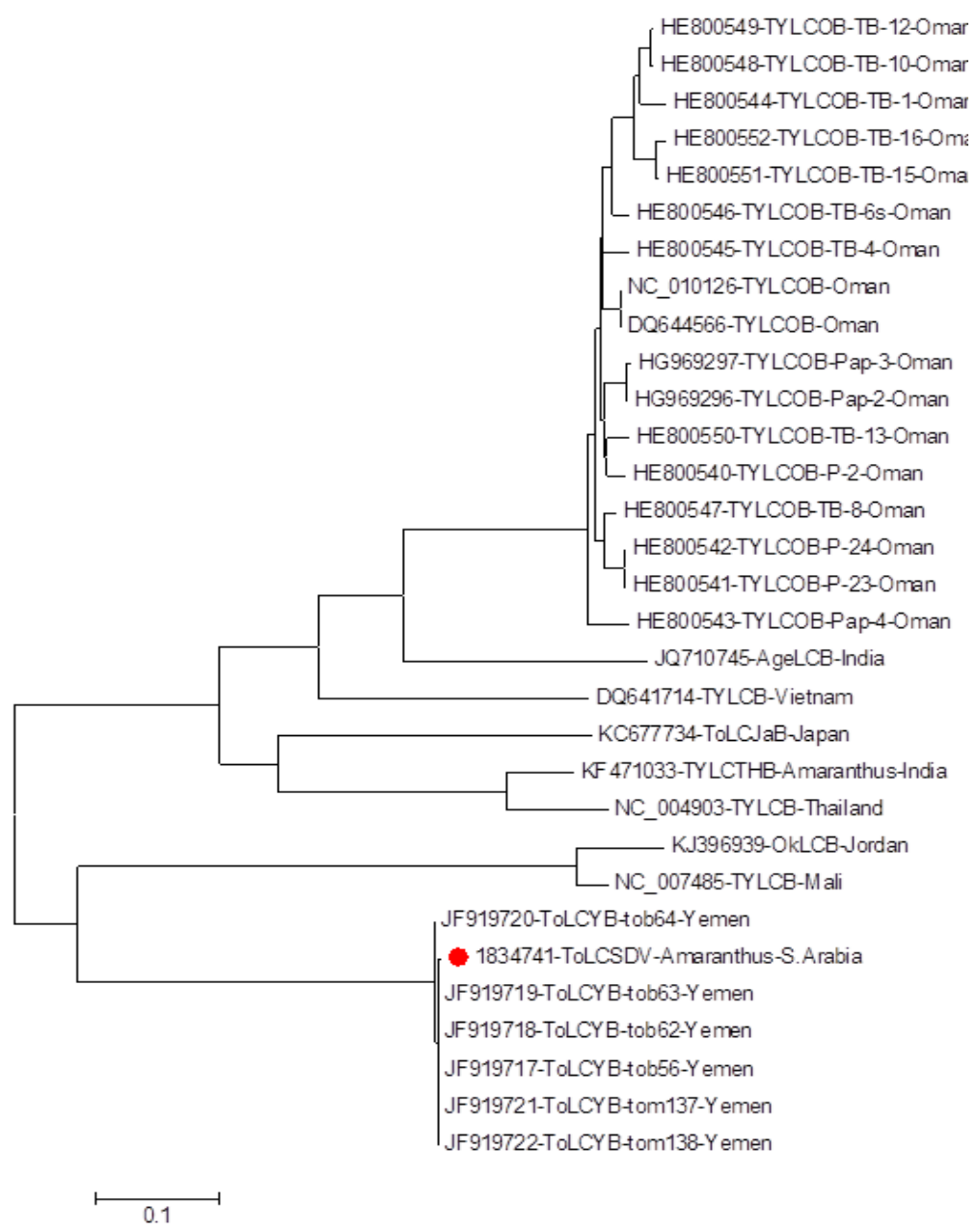

Fig 3. Phylogenetic relationships of betasatellites under study with selected strains (selected based on BLASTn analysis) determined by NJ method within MEGA v6.1 with 1000 bootstrap replicates.

Amaranth grain is a highly nutritional pseudo cereal with a superior amount of proteins and possesses anti allergic and antioxidant activities (Huputli and Jain 1977). Only a few reports are available in the literature about viruses infecting Amaranthus. The present study reports about a disease complex comprising a monopartite begomovirus, betasatellite associated with Amaranthus leaf curl disease in Jeddah, Saudi Arabia. Although the extent of the spread of this disease is not known, the results emphasize the greater impact of Tomato leaf curl Sudan virus by expanding its host range to Amaranthus crops. This disease may emerge as a serious threat to other crops grown in Saudi Arabia and thus, more detail studies are required to determine the diversity of begomoviruses and associated satellites infecting Amaranthus crops as well as other crops being cultivated in this region and serving as an alternative host for begomovirus. A survey of the literature revealed that Amaranthus is also infected by begomoviruses like AgEV (Srivastava et al., 2013), ChiLCV (George et al., 2014), PALCV (Srivastava et al., 2015) and Ageratum leaf curl has been reported from India (Srivastava et al., 2015).

Globally, the emergence of begomoviruses over the last 2030 years has become the most important groups of plant viruses affecting vegetables crop production due to increase of whitefly vector population in the tropics and subtropics and tomato leaf curl or tomato yellow leaf curl has become the most devastating viral disease worldwide which serves as source of inoculum to disease spread by whiteflies vector (Hanssen et al., 2010). The expansion and intensification of tomato cropping favored the increased populations of 
whiteflies (B. tabaci) with a wider expansion of leaf curl disease incidence in tomato crops. For the past two decades, tomato production in Arabian Peninsula and Nile Basin has been affected by leaf curl disease caused by begomovirus (Ajlan et al., 2007; Idris et al., 2012; Duffy and Holmes 2008). The presence of begomovirus and association of ToLCSDV causing leaf curl disease of tomato in Gezira, Sudan (Nile Basin) has been cloned and sequenced as early as 1996 (Idris and Brown 2005).It is more than likely that ToLCSDV isolates circulating in Saudi Arabia has originated either from Yemen or Oman, as the studied virus being the closest relative to the Saudi Arabian, Oman and Yemen isolates. In Oman tomato leaf curl disease was first identified in 1993 but the etiology of the disease was confirmed recently and the natural occurrence of ToLCSDV has been reported in Oman (Khan et al., 2013a). In Yemen, tomato leaf curl virus is associated with a betasatellites that have only been identified and known as Tomato yellow leaf curl Yemen betasatellites (Idris et al., 2012). On the other side, Yemen is separated from Oman and Saudi Arabia by a vast harsh desert condition which plays potential barriers to virus and whitefly movement. However, the extant occurrence in both locations of two closely related viruses indicates that what may serve as deterrents to human movement, do not present impervious barriers to virus-vector dispersal, having fostered instead the apparently, unrestricted natural dispersal of TYLCV and ToLCSDV isolates in the kingdom (Idris et al., 2011).

Based on results obtained from field survey, virus detection, sequence identity, phylogenetic relationship and recombination analysis, it is clear that the virus circulating in Saudi Arabia is a variant of ToLCSDV. The complete genome sequence identity showed the highest sequences identity with ToLCSDV isolate identified earlier from Saudi Arabia and betasatellites sequence identity with Tomato leaf curl Yemen betasatellites. The phylogenetic relationship results based on full genome and betasatellites also provided strong relationships with ToLCSDV isolates from Saudi Arabia, Yemen, and Oman. In field survey, leaf curl disease and presence of whitefly vector were observed in tomato crops and same kind of leaf curl disease was observed in Amaranthus crops also. So based on above results, it is obvious that the virus has been transmitted by whiteflies and causing leaf curl disease in Amaranthus growing in and around the tomato growing field in Jeddah, Saudi Arabia.

It is obvious that the expansion and intensification of cropping systems favor the emergence and increase the level of whitefly population and the emergence of begomovirus variants and acquisition of satellite DNA molecules with more aggressive or crop-adapted characteristics due to mutation, recombination, and pseudo-recombination. Apart from that, it is also suspected that there may the introduction and spread of begomovirus species from outside the region probably through the human movement, of infected plant materials, introduction of tolerant and susceptible tomato cultivars and climatic condition in the localized regions also promoted the favorable condition for the whiteflies vector and allowed the spread of the viruses in new areas (Kenyon et al., 2014). Here, it is ascertained the association of a begomovirus and the satellite molecules with leaf curl disease from Saudi Arabia. The presence of Alphasatellites and DNA-B could not be ascertained in the infected Amaranthus samples when degenerate primers were used (George et al., 2014). But we succeeded in the full genome amplification by RCA methods. However, the nature of the association of a monopartite begomovirus with betasatellite leading to leaf curl disease in Amaranthus is unclear which needs further experimentation. However, based on the literature and findings and the association of ToLCSDV with leaf curl disease of Amaranthus is the first report from Saudi Arabia. The present finding suggested that A. cruentus may serve as an alternative host for ToLCSDV and in near future, this virus may spread and cause disease to other crops growing in Saudi Arabia.

\section{Materials and methods}

\section{Field survey, sample collection and whitefly transmission}

In April 2014, during the field survey, leaf curl disease was observed on Amaranthus plants growing in and around farmer's field at Jeddah, Saudi Arabia. Symptomatic and non-symptomatic top emerging leaves were collected from field infected Amaranthus plant and immediately kept in ice with self-sealing plastic bags and brought to the lab for further processing. A fresh culture of non-viruliferous whitefly was raised from their un-hatched eggs and maintained on healthy eggplant under insect-proof condition. The adult whiteflies were allowed to feed on infected tomato leaves for $24 \mathrm{~h}$ for virus acquisition and then transferred onto healthy tomato seedlings (twenty whiteflies / seedling) to transmit the causal organism by giving $24 \mathrm{~h}$ inoculation access period under insect-proof cages. Total 21 healthy seedlings were inoculated in three replicates and kept under insect-proof condition for symptoms development for 25 days.

\section{Virus detection, cloning and sequencing}

Total genomic DNA was isolated from $100 \mathrm{mg}$ leaf tissue of infected as well as healthy Amaranthus plant using a DNeasy Plant Mini Kit (Qiagen GmbH, Hilden, Germany); and begomovirus infection was confirmed by polymerase chain reaction (PCR) using specific primers TYC1F (5'GGGCCTAGAGACCTG GCCCAC-3') and TYC1R (5'CCGGTAATATTATAC GGATGGC-3'), which amplify an 856-bp fragment of the 5' end of the C1 gene of TYLCV-IL (Hosseinzadeh et al., 2014). No amplicon was observed in healthy samples. The full-length genome was amplified by rolling circle amplification from symptomatic A. cruentus leaf sample using Phi-29 DNA polymerase (TempliPhi ${ }^{\mathrm{TM}}$ DNA amplification kit; GE Healthcare, Buckinghamshire, UK) as per manufacturer's instructions.

Total $3 \mu \mathrm{l}$ RCA amplified product was digested with EcoR1 and $2.7 \mathrm{~kb}$ fragments were separated and purified on $1 \%$ Agarose gel. The gel purified full-length genome $(\sim 2.7 \mathrm{~kb})$ was cloned into pGEM7Zf + (Promega, Madison, WI) and sequenced. The full-length betasatellites were amplified by using specific primers (Briddon et al., 2002) and cloned into a pGEMT-Easy vector (Promega, USA). The confirmed clones were bi-directionally sequenced in our lab by using primer walking methods and analyzed by using NCBI-BLAST.

\section{Sequence, phylogenetic and recombination analysis}

The full length sequences were aligned and the resulting nucleotide sequence was initially searched for similarity using the BLAST program (http://www.ncbi.nlm.nih.gov/BLAST/) (Altschul et al., 1997).The sequences that showed higher score and similarity were selected for further analysis. Multiple sequence alignments were performed by ClustalW program (http://www.ebi.ac.uk/clustalw) using nucleotides sequences 
of selected begomoviruses from the GenBank. A phylogenetic tree was constructed using MEGA v 6.1 program from the aligned nucleotide sequences with neighbor-joining and maximum parsimony methods using maximum composite likelihood for DNA substitution test (Tamura et al., 2013). The recombination detection program (RDP4) tool was used (darwin.uvigo.es/rdp/rdp.html) for detection of potential recombinant sequences, identification of likely parental sequences and localization of possible recombination breakpoints. The analysis was performed with default settings using a $0.05 P$-value cutoff and standard Bonferroni corrections for multiple testing ( Martin et al., 2015).

\section{Conclusion}

Based on results obtained from, field survey, virus detection, sequence identity, phylogenetic and recombination analysis using full genome and betasatellites genome, this study concludes that the identified virus could be a variant of ToLCSDV, a virus reported earlier from Sudan, Yemen, and Arabian Peninsula . This is the first report causing severe leaf curl disease of Amaranthus in Jeddah, Saudi Arabia.

\section{Acknowledgments}

Author would like to thank General directorate of Research Grants (GDRG), King Abdulaziz City for science and technology (KACST-Riyadh) for providing a large grant, bearing number: AT-66-34.The author would also like to gratefully acknowledge the research facility provided by Special Infectious Agents Unit, King Fahd Medical Research Center (KFMRC), King Abdulaziz University, Jeddah, Saudi Arabia.

\section{Competing interests:}

The author declares that they have no conflict of interest.

\section{References}

Abou-Jawdah Y, Maalou FR, Shebaro W, Soubra K (1999) Comparison of the reaction of tomato lines to infection by Tomato yellow leaf curl begomovirus in Lebanon. Plant Pathol. 48: 727-734.

Ajlan AM, Ghanem GAM, Abdulsalam KS (2007) Tomato yellow leaf curl virus (TYLCV) in Saudi Arabia:Identification, partial characterization and virusvector relationship. Arab J Biotech. 10: 179-192.

Akhtar S, Khan AJ, Singh AK, Briddon RW (2014) Identification of a disease complex involving a novel monopartite begomovirus with beta- and alphasatellites associated with okra leaf curl disease in Oman. Arch Virol. 159: 1199-1205.

Al-Saleh MA, Al-Shahwan IM, Brown JK, Idris AM (2014) Molecular characterization of a naturally occurring intraspecific recombinant begomovirus with close relatives widespread in southern Arabia. Virol J. 11:103.

Altschul SF, Thomas LM, Alejandro AS, Zhang J, Zhang Z, Miller W, Lipman DJ (1997) Gapped BLAST and PSIBLAST: a new generation of protein database search programs. Nucl Acids Res. 25: 3389-3402.

Bhatia AL (2005) Growing colorful and nutritious Amaranths.Indian Journal of Natural Products \& Resources, 4: 40-43.
Briddon RW, Bull SE, Mansoor S, Amin I, Markham PG (2002) Universal primers for the PCR-mediated amplification of DNA $\beta$; a molecule associated with some monopartite begomoviruses. Mol Biotec. 20:315-318.

Briddon RW, Bull SE, Amin I, Idris AM, Mansoor S, Bedford ID (2003) Diversity of DNA beta, a satellite molecule associated with some monopartite begomoviruses. Virology. 312: 106-121.

Briddon RW, Mansoor S, Bedford ID, Pinner MS, Saunders K, Stanley J (2001) Identification of dna components required for induction of cotton leaf curl disease. Virology. 285: 234-243.

Brown JK, Zerbini FM, Navas-Castillo J, Moriones E, Ramos-Sobrinho R, Silva JCF (2015) Revision of Begomovirus taxonomy based on pairwise sequence comparisons. Arch Virol. 160: 1593-1619.

Brunt AA, Crabtree K, Dallwitz MJ, Gibbs AJ, Watson L, Zurcher EJ (1996) Plant Viruses Online: Descriptions and Lists from the VIDE Database. Version.

Costea M, Tardif FJ (2003) The Biology of Canadian Weeds 126. Amaranthus albus L., A. blitoides S. Watson and A. blitum L. Biology Faculty Publications. 83:1039-66.

Duffy S, Holmes EC (2008) Phylogenetic evidence for rapid rates of molecular evolution in the single-stranded DNA begomovirus tomato yellow leaf curl virus. Journal of Virology. 82: 957-965.

Fauquet CM, Briddon RW, Brown JK, Moriones E, Stanley J, Zerbini M (2008) Geminivirus strain demarcation and nomenclature. Arch Virol. 153: 783-821.

George B, Vinoth KR, Chakraborty S (2014) Molecular characterization of Chili leaf curl virus and satellite molecules associated with leaf curl disease of Amaranthus spp. Virus Genes. 48: 397-401.

Hanssen IM, Lapidot M, Thomma BPHJ (2010) Emerging viral diseases of tomato crops. Molecular Plant-Microbe Interactions: 23: 539-548.

Hauptli H, Jain S (1977) Amaranth and meadowfoam: Two new crops?. Cal Ag. 31: 6-7.

Horvath J (1991) Amaranthus species (Family Amaranthaceae) as host of plant viruses: a review. Acta Phytopatho Entomo Hungarica. 26: 385-422.

Hosseinzadeh MR, Bakhsh MS, Osaloo SK, Brown, JK (2014) Phylogenetic relationships, recombination analysis, and genetic variability among diverse variants of tomato yellow leaf curl virus in Iran and the Arabian Peninsula: further support for a TYLCV center of diversity. Arch Virol. 159: 485-497.

Idris A, Al-Saleh M, Piatek MJ, Al-Shahwan I, Ali S, Brown JK (2014) Viral Metagenomics: Analysis of Begomoviruses by Illumina High-Throughput Sequencing. Viruses. 6: 1219-1236.

Idris AM, Brown JK (2005) Evidence for interspecificrecombination for three monopartite begomoviral genomes associated with the tomato leaf curl disease from central Sudan. Arch Virol. 150: 1003-1012.

Idris AM, Abdullah NM, Brown JK (2012) Leaf curl diseases of two Solanaceous species in Southwest Arabia are caused by a monopartite begomovirus evolutionarily most closely related to a species from the Nile Basin and unique suite of betasatellites. Virus Res. 169: 296-300.

Idris AM, Shahid MS, Briddon RW, Khan AJ, Zhu JK, Brown JK (2011) An unusual alphasatellite associated with monopartite begomoviruses attenuates symptoms and reduces betasatellite accumulation. J G Virol. 92: 706-717.

Kenyon L, Tsai WS, Shih SL, Lee LM. (2014). Emergence and diversity of begomoviruses infecting solanaceous crops in East and Southeast Asia. Virus Research. 186: 104-113. 
Khan AJ, Akhtar S, Singh AK, Briddon RW (2013a) A distinct strain of Tomato leaf curl Sudan virus causes tomato leaf curl disease in Oman. Plant Dis. 97: 13961402.

Khan AJ, Akhtar S, Al-Zaidia AM, Singh AK, Briddon RW (2013b) Genetic diversity and distribution of a distinct strain of Chili leaf curl virus and associated betasatellite infecting tomato and pepper in Oman. Virus Res. 177: 8797.

Khan AJ, Idris AM, Al-Saady NA, Al-Mahruki MS, AlSubhi AM Brown JK (2008) A divergent isolate of Tomato yellow leaf curl virus from Oman with an associated DNA b satellite: an evolutionary link between Asian and the Middle Eastern virus-satellite complexes. Virus Genes. 36: 169-176.

Martin DP, Michael GBM, Khoosal A, Muhire B (2015) RDP4: Detection and analysis of recombination patterns in virus genomes. Virus Evolution. 1: vev003.

Muhire BM, Varsani A, Martin DP (2014) SDT: a virus classification tool based on pairwise sequence alignment and identity calculation. PloS One. 9:e108277.

Raj SK, Snehi SK, Khan MS, Chandra P, Pandey RM (2008) First molecular identification of a begomovirus associated with yellow vein net disease in grain amaranth (Amaranthus cruentus L.) in India. Australasian Plant Dis Notes. 3: 129-131.

Segundo E, Lesemann D, Martín G, Carmona M, Ruiz L, Cuadrado I (2007) Amaranthus leaf mottle virus: 3'-end RNA sequence proves classification as distinct virus and reveals affinities within the genus Potyvirus. EuroJ Plant Pathol. 117: 81-87.
Sharma A, Kulshrestha S (2014) First report of Amaranthus sp. as a natural host of capsicum chlorosis virus in India. Virus Disease. 25: 412-413.

Sivalingam PN, Malathi VG, Varma A (2010) Molecular diversity of the DNA-beta satellites associated with tomato leaf curl disease in India. Arch Virol. 155: 757-764.

Srivastava A, Raj SK, Kumar S, Snehi SK, Kulshreshtha A, Hallan V (2013) Molecular identification of Ageratum enation virus, betasatellite and alpha satellite molecules isolated from yellow vein diseased Amaranthus cruentus in India. Virus Genes. 47: 584-590.

Srivastava A, Jaidi M, Kumar S, Raj SK, Shukla S (2015) Association of Papaya leaf curl virus with the leaf curl disease of grain amaranth (Amaranthus cruentus L.) in India. Phytoparasitica. 43:97-101.

Srivastava A, Raj SK (2004) High molecular similarity among Indian isolates of Cucumber mosaic virus suggests a common origin. Curr Sci. 87: 1126-1131.

Tamura K, Stecher G, Peterson D, Filipski A, Kumar S. (2013). MEGA 6: Molecular evolutionary genetics analysis version 6.0. Mol Biol Evo. 30: 2725-2729.

Varsani A, Navas-Castillo J, Moriones E, Hernández-Zepeda C, Idris A, Brown JK. (2014). Establishment of three new genera in the family Geminiviridae: Becurtovirus, Eragrovirus and Turncurtovirus. Arch Virol. 159: 21932203. 